\title{
Echocardiographic Predictors of Remote Outcome in Patients With Angiographically Successful Reflow After Acute Myocardial Infarction
}

\author{
Jinyao Liu, MD; Nobuaki Tanaka, MD*; Kazuya Murata, MD; Kayo Ueda, MD; \\ Yasuaki Wada, MD; Rikimaru Oyama, MD; Yoko Hamada, MD; \\ Yasuyuki Hadano, MD; Takashi Fujii, MD; Masunori Matsuzaki, MD
}

\begin{abstract}
Background The angiographically no-reflow phenomenon after percutaneous coronary intervention (PCI) predicts poor left ventricular (LV) functional recovery and a high risk of cardiac events in patients with their first acute myocardial infarction (AMI). However, risk factors of long-term adverse outcome for patients with angiographically successful reflow (TIMI (Thrombolysis in Myocardial Infarction) flow grade 3) for the AMI remain unknown.

Methods and Results Of 168 echocardiograms were performed before PCI and at discharge, 113 were suitable for analysis. Clinical, angiographic, and echocardiographic variables were submitted to statistical analysis to detect the risk factors of cardiac events. During the follow-up period of $46 \pm 20$ months, 31 patients had cardiac events, though there were no cardiac deaths. The 2 most important risk factors for congestive heart failure (CHF) or total cardiac events were LV dilation (chi-square: 7.5 and 9.4; both $\mathrm{p}<0.01$ ) and pseudonormal transmitral flow pattern (PN, chi-square: 4.9, $\mathrm{p}<0.05$ and $6.7, \mathrm{p}<0.01$, respectively). However, only multivessel disease (chisquare: 9.4, $\mathrm{p}=0.05$ ) became the predictor for revascularization after PCI. The incidence of CHF or total cardiac events in patients with PN and LV dilation at discharge determined by the Kaplan-Meier method were significantly higher than those with normal or abnormal relaxation transmitral flow pattern (log-rank: 41 and 27, both $\mathrm{p}<0.001)$ and no LV dilation (log-rank: 20 and 20, both $\mathrm{p}<0.001)$.

Conclusion Poor LV diastolic function and LV dilation at discharge are predictors of the cardiac events in patients in whom epicardial coronary flow was well-restored after PCI for the first AMI. (Circ J 2004; 68: 1004-1010)
\end{abstract}

Key Words: Acute myocardial infarction; Cardiac events; Echocardiography; Percutaneous coronary intervention

$\mathbf{P}$ ercutaneous coronary intervention (PCI) is now routine for patients with acute myocardial infarction (AMI), and is increasingly used to treat complex coronary lesions with good long-term outcome. However, in the multicenter Lescol Intervention Prevention Study, the annual risk of a major adverse cardiac event, defined as cardiac death, nonfatal myocardial infarction (MI) or a reintervention procedure (eg, coronary artery bypass grafting $(\mathrm{CABG})$, repeat PCI, or PCI for a new lesion) approached $7 \%$.

Early restoration of coronary antegrade flow limits the progression of myocardial necrosis and is thus expected to enhance the functional recovery of postischemic dysfunction of the myocardium in patients with $\mathrm{AMI}^{2-4}$ Previous studies have demonstrated that 'angiographic no-reflow' predicts poor left ventricular (LV) functional recovery and a higher risk of cardiac mortality during the early phase and

(Received February 2, 2004; revised manuscript received August 2, 2004; accepted August 19, 2004)

Department of Cardiovascular Medicine, Yamaguchi University School of Medicine and *Department of Clinical Laboratory, Yamaguchi University Hospital, Ube, Japan

Mailing address: Masunori Matsuzaki, MD, FACC, Department of Cardiovascular Medicine, Yamaguchi University School of Medicine, 1-1-1 Minami-Kogushi, Ube, Yamaguchi 755-8505, Japan. E-mail: masunori@yamaguchi-u.ac.jp long-term follow-up period in patients with AMI5,6 However, the long-term prognosis after AMI remains unexplored in patients with angiographically successful reflow (TIMI (Thrombolysis in Myocardial Infarction) flow grade 3) after PCI.

Several recent studies have proved the clinical usefulness of echocardiography in predicting outcome in patients with congestive heart failure (CHF), $\mathrm{AMI}^{8}$ and $\mathrm{CABG}^{9}$, but its long-term prognostic value in patients with angiographically successful reflow after AMI is unknown. Thus, in the present study we analyzed the long-term prognostic value of echocardiography in a consecutive series of patients with complete coronary revascularization by primary PCI for an initial AMI.

\section{Methods}

\section{Patient Population}

Of 168 consecutive patients with AMI who were treated at Yamaguchi University Hospital, Japan, between January 1995 and January 2000, 113 (82 men, 31 women; age 46-84 years) were enrolled in the study. Criteria for inclusion were: (1) initial AMI; (2) a single-culprit lesion; (3) the infarct-related artery was recanalized with direct or rescue-PCI within $6 \mathrm{~h}$ of onset or between 6 and $24 \mathrm{~h}$ if evidence showed continuing ischemia; (4) residual stenosis 
Table 1 Clinical and Angiographic Characteristics of the Patients With an Initial AMI

\begin{tabular}{lccc}
\hline \hline & $\begin{array}{c}\text { Total cardiac events } \\
(n=31)\end{array}$ & $\begin{array}{c}\text { No events } \\
(n=82)\end{array}$ & $p$ value \\
\hline Age (years) & $65 \pm 9$ & $66 \pm 10$ & 0.843 \\
Male & $26(84 \%)$ & $56(69 \%)$ & 0.160 \\
Coronary risk factors & & & \\
$\quad$ Diabetes mellitus & $12(39 \%)$ & $26(32 \%)$ & 0.629 \\
Systemic hypertension & $15(48 \%)$ & $44(54 \%)$ & 0.771 \\
Hyperlipidemia & $25(81 \%)$ & $45(55 \%)$ & 0.021 \\
Smoking index & $684 \pm 572$ & $658 \pm 836$ & 0.874 \\
Anteroseptal infarction & $14(45 \%)$ & $44(54 \%)$ & 0.550 \\
Ischemic time (h) & $4.9 \pm 5.0$ & $4.4 \pm 3.2$ & 0.528 \\
Forrester subset $>2$ on admission & $11(35 \%)$ & $14(17 \%)$ & 0.044 \\
Collateral grade $<2$ & $24(77 \%)$ & $73(89 \%)$ & 0.201 \\
Multivessel disease & $22(70 \%)$ & $38(46 \%)$ & 0.033 \\
Left main coronary artery disease & $4(13 \%)$ & $1(1 \%)$ & 0.028 \\
Peak creatine kinase (IU/L) & $3,847 \pm 2,760$ & $3,160 \pm 2,791$ & 0.245 \\
Malignant arrhythmia & $8(25 \%)$ & $16(17 \%)$ & 0.652 \\
In-hospital time (days) & $51 \pm 18$ & $43 \pm 14$ & 0.009 \\
Medications & & & 0.273 \\
Angiotensin-converting enzyme inhibitors & $30(96 \%)$ & $71(88 \%)$ & 0.295 \\
$\beta$-adrenergic blockers & $11(35 \%)$ & $19(24 \%)$ & 0.995 \\
Long-acting nitrates & $28(90 \%)$ & $75(93 \%)$ & 0.843 \\
Diuretics & $2(6 \%)$ & $8(10 \%)$ & $<0.0001$ \\
Follow-up time (months) & $33 \pm 23$ & $51 \pm 16$ & \\
\hline
\end{tabular}

no more than $50 \%$ and TIMI flow grade 3 achieved after PCI; and (5) absence of apparent dissection or thrombosis that might restrict coronary flow. Patients excluded from the study were those with recurrent AMI $(\mathrm{n}=22)$, angiographic low-flow or no-reflow (TIMI $\leq 2, \mathrm{n}=12$ ), atrial fibrillation $(n=3)$, valvular aortic stenosis $(n=3)$, greater than grade $2 / 4$ mitral regurgitation on echocardiography $(n=5)$, chronic renal failure $(n=5)$, and those who underwent emergency CABG $(n=5)$. Patients who already had cardiac complications, including recurrent angina pectoris, recurrent myocardial infarction or cardiac rupture, or who died during their hospitalization period were also excluded from analysis of cardiac event-free survival. The Institutional Review Board of Yamaguchi University Hospital approved the study.

\section{Coronary Angiography and Angioplasty}

All angiograms were analyzed by 2 experienced observers and discrepancies were resolved by consensus. In all patients, the infarct-related artery was analyzed before and after PCI. Contrast flow through the epicardial vessel during angiography was graded according to the standard TIMI trial flow scale $0-3,^{10}$ and retrograde collateral flow was scored according to the classification of Rentrop et all11 TIMI trial flow grade 3 was considered as angiographically successful reflow, and the presence of grade 2 or 3 collateral flow was considered significant. Multivessel disease was defined as $\geq 51 \%$ stenosis in either 2 or all 3 major epicardial coronary arteries. Left main coronary artery disease was defined as $40 \%$ diameter stenosis. By definition, all the patients in this study had TIMI 3 flow of the culprit vessel restored after PCI.

\section{Echocardiography}

Echocardiography was performed with the patients in the left lateral decubitus position. M-mode, 2-dimensional, pulsed Doppler and color Doppler echocardiographic studies were done with a phased array color Doppler echocardiographic unit (SSD-2200 or SSD-5500, ALOKA Co, Ltd, Tokyo, Japan) with a $2.5 \mathrm{MHz}$ transducer.
Transmitral flow (TMF), pulmonary venous flow (PVF), LV end-diastolic and end-systolic diameters (LVDd and LVDs), LV ejection fraction (LVEF), and LV wall motion score index (LVWMSI) were analyzed before PCI and within 1 week of discharge after PCI when the patients were stable and the loading condition was controlled well with medication.

The LV wall was divided according to a 16-segment model ${ }^{12}$ and for each segment, wall motion was scored as 1 (normal), 2 (hypokinetic), 3 (akinetic), or 4 (dyskinetic). The LVWMSI was obtained by adding the score of all examined segments and dividing it by the number of segments scored. Each echocardiographic examination was recorded on videotape and evaluated by 2 experienced observers. LVDd, LVDs, and LVEF were obtained by 2-dimensional guided M-mode echocardiography; LVDd $\geq 55 \mathrm{~mm}$ for males or $\geq 50 \mathrm{~mm}$ for females was considered as LV dilation.

According to the method of a previous study, TMF was classified into 4 patterns: (1) normal pattern $(\mathrm{N})$, characterized by $\mathrm{E} / \mathrm{A}>1$, normal deceleration time (180-220 ms), and the ratio of $\mathrm{A}$-wave duration in TMF to that in $\mathrm{PVF}>1$; (2) abnormal relaxation pattern $(\mathrm{Ab})$, characterized by a prolonged deceleration time $(\geq 220 \mathrm{~ms}), \mathrm{E} / \mathrm{A} \leq 1$, and the ratio of A-wave duration in TMF to that in $\mathrm{PVF}>1$; (3) pseudonormal pattern $(\mathrm{PN})$, characterized by a shortened deceleration time $(150-180 \mathrm{~ms}), 1<\mathrm{E} / \mathrm{A}<2$, and the ratio of A-wave duration in TMF to that in $\mathrm{PVF}<1$; and (4) restrictive pattern, characterized by a shortened deceleration time $(\leq 150 \mathrm{~ms}), \mathrm{E} / \mathrm{A} \geq 2$, and the ratio of $\mathrm{A}$-wave duration in TMF to that in $\mathrm{PVF}<1$.

\section{In-Hospital Clinical Course}

Adjunctive medical therapy followed the standards of the coronary care unit. The following data were obtained: age, gender, coronary risk factors (eg, systemic hypertension, diabetes mellitus, hyperlipidemia, and smoking), serum creatine kinase concentrations, malignant arrhythmia (excluding reperfusion arrhythmia), ischemic time, and pump failure. Systemic hypertension was defined as systol- 
Table 2 Echocardiographic Characteristics of the Patients With an Initial AMI

\begin{tabular}{|c|c|c|c|c|}
\hline & \multicolumn{2}{|c|}{ Total cardiac events $(n=31)$} & \multicolumn{2}{|c|}{ No events $(n=82)$} \\
\hline & Before PCI & At discharge & Before PCI & At discharge \\
\hline $\operatorname{LVDd}(\mathrm{mm})$ & $49 \pm 6$ & $50 \pm 6$ & $48 \pm 5$ & $48 \pm 6^{\dagger}$ \\
\hline Dilation & $5(16 \%)$ & $18(58 \%) *$ & $10(12 \%)$ & $8(10 \%)+\dagger$ \\
\hline No dilation & $26(84 \%)$ & $13(42 \%) *$ & $72(88 \%)$ & $74(90 \%)+t$ \\
\hline LVDs (mm) & $34 \pm 6$ & $34 \pm 7$ & $34 \pm 6$ & $32 \pm 7 * \dagger$ \\
\hline LVWMSI & $1.7 \pm 0.4$ & $1.7 \pm 0.6$ & $1.7 \pm 0.4$ & $1.5 \pm 0.4 *, \dagger$ \\
\hline$<1.5$ & $7(23 \%)$ & $13(42 \%) *$ & $32(39 \%)^{\dagger}$ & $42(51 \%) * \dagger$ \\
\hline$\geq 1.5$ & $24(77 \%)$ & $18(58 \%) *$ & $50(61 \%)^{\dagger}$ & $40(49 \%)^{*, t}$ \\
\hline LVEF & $44 \pm 9$ & $46 \pm 8$ & $44 \pm 8$ & $50 \pm 7 *,+$ \\
\hline$\geq 55 \%$ & $3(10 \%)$ & $6(19 \%)$ & $6(7 \%)$ & $20(24 \%) *$ \\
\hline $41-54 \%$ & $12(39 \%)$ & $17(55 \%) *$ & $49(60 \%)^{\dagger}$ & $53(65 \%)^{\dagger}$ \\
\hline$\leq 40 \%$ & $16(51 \%)$ & $8(26 \%) *$ & $27(33 \%)^{\dagger}$ & $9(11 \%)^{* \dagger}$ \\
\hline \multicolumn{5}{|l|}{ Transmitral flow pattern } \\
\hline Normal & 0 & $5(17 \%)$ & 0 & $18(22 \%)$ \\
\hline Abnormal relaxation & $12(39 \%)$ & $11(35 \%)$ & $41(50 \%)^{\dagger}$ & $56(68 \%) *+t$ \\
\hline Pseudonormal & $7(22 \%)$ & $15(48 \%) *$ & $26(32 \%)$ & $8(10 \%) * t$ \\
\hline Restrictive pattern & $12(39 \%)$ & 0 & $15(18 \%)^{\dagger}$ & 0 \\
\hline
\end{tabular}

${ }^{*} p<0.05$ vs before $P C I,{ }^{\dagger} p<0.05$ vs total cardiac events group, ${ }^{\dagger} p<0.01$ vs total cardiac events group.

AMI, acute myocardial infarction; LVDd, left ventricular diastolic dimension; LVDs, LV systolic dimension; LVEF, LV ejection fraction; LVWMSI, LV wall motion score index.

Table 3 Risk Predictors for Congestive Heart Failure During Long-Term Follow-up Period in Univariate Cox Proportional Hazards Regression Model

\begin{tabular}{|c|c|c|c|c|}
\hline & $\begin{array}{c}\text { Chi-square } \\
\text { value }\end{array}$ & $p$ value & $\begin{array}{c}\text { Exponential of } \\
\text { coefficient }\end{array}$ & $\begin{array}{c}95 \% \text { confidence } \\
\text { interval }\end{array}$ \\
\hline \multicolumn{5}{|l|}{ Coronary risk factor } \\
\hline Diabetes mellitus & 3.34 & 0.0677 & 2.44 & $0.94-6.39$ \\
\hline Systemic hypertension & 1.41 & 0.2352 & 0.55 & $0.21-1.47$ \\
\hline Hyperlipidemia & 0.52 & 0.4703 & 1.47 & $0.52-4.17$ \\
\hline Smoking index & 0.04 & 0.8333 & 1.00 & $1.00-1.01$ \\
\hline Anteroseptal infarction & 0.61 & 0.4346 & 1.47 & $0.56-3.90$ \\
\hline Ischemic time $(h)$ & 0.03 & 0.8632 & 1.01 & $0.89-1.15$ \\
\hline Peak creatine kinase (IU/L) & 0.74 & 0.3894 & 1.00 & $1.00-1.00$ \\
\hline Malignant arrhythmia & 1.17 & 0.2806 & 1.74 & $0.64-4.78$ \\
\hline Collateral grade $<2$ & 0.05 & 0.8240 & 0.92 & $0.45-1.88$ \\
\hline Left main coronary artery disease & 0.03 & 0.8684 & 1.01 & $0.89-1.15$ \\
\hline Multivessel disease & 3.96 & 0.0466 & 2.93 & $1.02-8.46$ \\
\hline Forrester subset $>2$ on admission & 10.89 & 0.0010 & 5.03 & $1.93-13.15$ \\
\hline Pseudonormal filling pattern & 19.94 & 0.0001 & 1.97 & $1.96-1.99$ \\
\hline LVDd dilation & 13.75 & 0.0002 & 7.22 & $2.54-20.54$ \\
\hline$L V E F \leq 40 \%$ & 10.58 & 0.0012 & 1.06 & $1.00-1.12$ \\
\hline$L V W M S I \geq 1.5$ & 6.52 & 0.0107 & 5.09 & $1.46-17.73$ \\
\hline In-hospital time (days) & 0.46 & 0.4966 & 1.01 & $0.98-1.05$ \\
\hline
\end{tabular}

Abbreviations see Table 2.

ic blood pressure $>140 \mathrm{mmHg}$ and/or diastolic blood pressure $>90 \mathrm{mmHg}$; diabetes mellitus was defined as fasting blood sugar $\geq 140 \mathrm{mg} / \mathrm{dl}$ or blood sugar during a 75 -g oral glucose tolerance test of $\geq 200 \mathrm{mg} / \mathrm{dl}$; hyperlipidemia was defined as total cholesterol $\geq 220 \mathrm{mg} / \mathrm{dl}$; malignant arrhythmia included sustained ventricular tachycardia, ventricular fibrillation, or high degree atrioventricular block; pump failure was defined as Forrester's subset class $>2$.

\section{Analysis of Follow-up Data}

Patients were seen every month at the outpatient clinic of Yamaguchi University Hospital and the follow-up data were assessed in February 2003, by which time all patients had completed the minimal follow-up period of 3 years (mean 46 \pm 20 months). Data were obtained from hospital charts and supplemented by records from the patient's general physicians. No patient was lost from follow-up. A cardiac event was defined as one of the following: (1) CHF; (2) recurrent AMI and/or a re-intervention procedure (eg, repeat PCI, or PCI for a new lesion) for unstable angina pectoris requiring hospitalization; or (3) CABG.

\section{Statistical Analysis}

Continuous data are expressed as mean \pm SD. Baseline data were compared by means of the chi-square test for categorical variables and t-test for continuous variables. Cardiac event-free survival curves were constructed by Kaplan-Meier method. Statistical differences between curves were assessed with the log-rank test. The univariate Cox proportional hazards regression model was used for each separate variable for cardiac events as dependent variables. Finally, multiple logistic regression analyses, containing clinical, angiographic, and echocardiographic variables, were performed to assess the independent contribution of different variables for the risk of cardiac events during the follow-up period. A p-value $<0.05$ was considered significant. Statistical analysis was performed using StatView for Windows version 5.0 (SAS Institute Inc, 
1998, Cary, NC, USA).

\section{Results}

\section{Baseline Patient Characteristics}

During the follow-up period ( $46 \pm 20$ months), 2 patients $(1.8 \%)$ were rehospitalized for nonfatal recurrent AMI, $11(9.7 \%)$ for $\mathrm{CHF}$ and $13(11.5 \%)$ for unstable angina pectoris, and 5 patients (4.4\%) underwent CABG for coronary revascularization. The clinical and angiographic characteristics of the patients are shown in Table 1. Compared with the patients in the no cardiac events group, those in the cardiac events group presented more often with hyperlipidemia, Forrester subset class $>2$, multivessel disease, left main coronary artery disease on admission, longer inhospital time, and shorter follow-up time period. Similar proportions of the 2 groups received angiotensin-converting enzyme inhibitors, $\beta$-blockers, long-acting nitrates, and diuretics.

\section{Cardiac Size and Function Based on Echocardiography}

Although LVDd, LVDs, LVWMI, and LVEF on admission were similar in both groups, cases of relatively greater LVWMI or lower LVEF were found in the event group (Table 2).

\section{Independent Predictors of Cardiac Events}

Congestive Heart Failure When only CHF was considered as the outcome event in the univariate analysis, the patients who rehospitalized for CHF presented with more frequent multivessel disease, Forrester subset class $>2$ on admission, PN, LV dilation, decreased LVEF $(\leq 40 \%)$, and increased LVWMSI $(\geq 1.5)$ on discharge (Table 3$)$. Howev$\mathrm{er}$, in the multivariate logical regression analysis, only PN (chi-square: 4.9, $\mathrm{p}<0.05$ ), and LV dilation (chi-square: 7.5, $\mathrm{p}<0.01)$ at discharge were the most powerful predictors of CHF.

CHF-free survival curves showed a significantly poor prognosis in patients with $\mathrm{PN}$ and $\mathrm{LV}$ dilation at discharge than in patients with the $\mathrm{N}$ or $\mathrm{Ab}$ relaxation pattern (Fig 1A) and no LV dilation (Fig 1B).
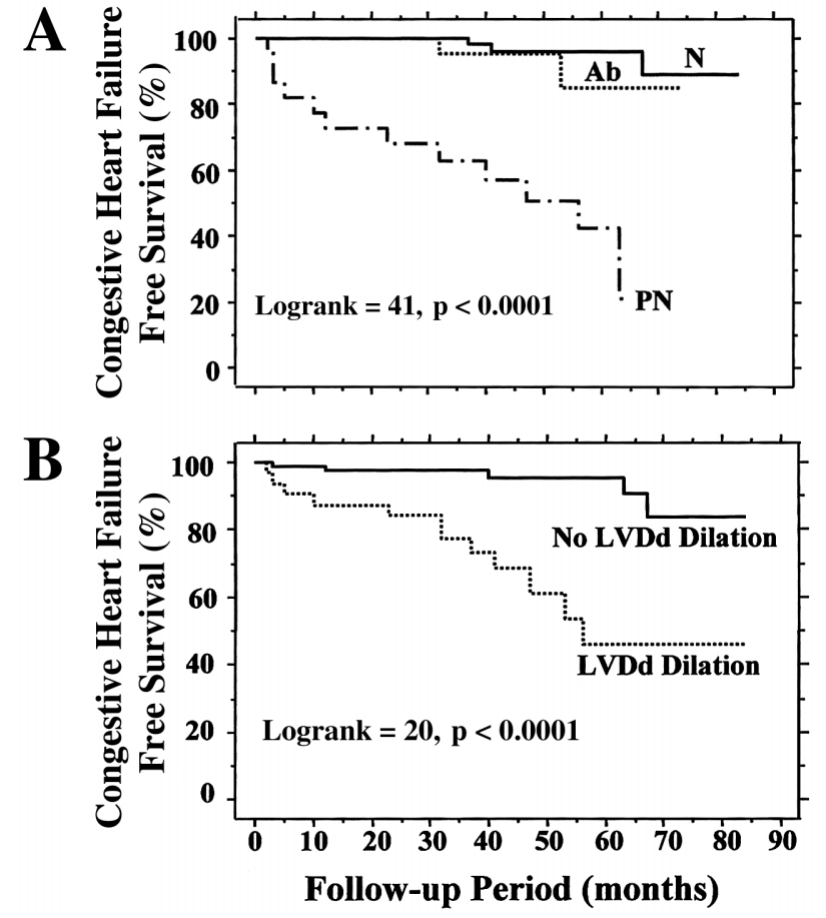

Fig 1. Kaplan-Meier survival curves drawn for congestive heart failure events only in patients stratified by their transmitral flow pattern (A) and left ventricular end-diastolic diameter (B) on discharge after percutaneous coronary intervention. $\mathrm{N}$, normal transmitral flow pattern; Ab, abnormal relaxation pattern; $\mathrm{PN}$, pseudonormal transmitral flow pattern; LVDd, left ventricular end-diastolic diameter.

Revascularization When repeat PCI, PCI for a new lesion, or CABG after PCI for recurrent AMI and unstable angina pectoris were considered as the outcome events in the univariate analysis, patients with one of the events presented more often with frequent hyperlipidemia, retrograde collateral flow grade 0 or 1 , left main coronary artery disease, and multivessel disease (Table 4). However, in the multivariate logical regression analysis, only multivessel

Table 4 Risk Predictors for Revascularization After PCI During Long-Term Follow-up Period in Univariate Cox Proportional Hazards Regression Model

\begin{tabular}{|c|c|c|c|c|}
\hline & $\begin{array}{c}\text { Chi-square } \\
\text { value }\end{array}$ & $p$ value & $\begin{array}{l}\text { Exponential of } \\
\text { coefficient }\end{array}$ & $\begin{array}{l}95 \% \text { confidence } \\
\text { interval }\end{array}$ \\
\hline \multicolumn{5}{|l|}{ Coronary risk factor } \\
\hline Diabetes mellitus & 0.63 & 0.4264 & 0.59 & $0.15-2.28$ \\
\hline Systemic hypertension & 0.06 & 0.8086 & 1.15 & $0.37-3.62$ \\
\hline Hyperlipidemia & 8.79 & 0.0030 & 10.69 & $1.34-85.6$ \\
\hline Smoking index & 0.01 & 0.9709 & 1.00 & $0.99-1.00$ \\
\hline Anteroseptal infarction & 3.09 & 0.0785 & 0.35 & $0.10-1.19$ \\
\hline Ischemic time $(h)$ & 0.93 & 0.3347 & 0.93 & $0.82-1.07$ \\
\hline Peak creatine kinase (IU/L) & 0.01 & 0.9449 & 1.00 & $1.00-1.00$ \\
\hline Malignant arrhythmia & 0.23 & 0.6338 & 0.69 & $0.14-3.38$ \\
\hline Collateral grade $<2$ & 11.82 & 0.0006 & 0.41 & $0.25-0.69$ \\
\hline Left main coronary artery disease & 11.73 & 0.0006 & 32.40 & $3.28-31.93$ \\
\hline Multivessel disease & 3.10 & 0.0425 & 2.89 & $1.84-9.98$ \\
\hline Forrester subset $>2$ on admission & 0.69 & 0.7925 & 0.81 & $0.16-4.03$ \\
\hline Pseudonormal filling pattern & 1.42 & 0.4924 & 0.44 & $0.07-2.70$ \\
\hline LVDd dilation & 3.71 & 0.0541 & 3.35 & $1.01-11.1$ \\
\hline$L V E F \leq 40 \%$ & 0.79 & 0.6730 & 0.45 & $0.05-3.72$ \\
\hline$L V W M S I \geq 1.5$ & 0.07 & 0.9328 & 1.05 & $0.34-3.26$ \\
\hline In-hospital time (days) & 0.11 & 0.7414 & 0.99 & $0.95-1.03$ \\
\hline
\end{tabular}

Abbreviations see Table 2. 
Table 5 Risk Predictors for Total Cardiac Events During Long-Term Follow-up Period in Univariate Cox Proportional Hazards Regression Model

\begin{tabular}{lcccc}
\hline \hline & $\begin{array}{c}\text { Chi-square } \\
\text { value }\end{array}$ & $p$ value & $\begin{array}{c}\text { Exponential of } \\
\text { coefficient }\end{array}$ & $\begin{array}{c}95 \% \text { confidence } \\
\text { interval }\end{array}$ \\
\hline Coronary risk factor & & & & \\
$\quad$ Diabetes mellitus & 0.48 & 0.4866 & 1.29 & $0.63-2.68$ \\
$\quad$ Systemic hypertension & 0.48 & 0.4874 & 0.78 & $0.38-1.58$ \\
Hyperlipidemia & 4.25 & 0.0392 & 2.55 & $1.04-6.23$ \\
$\quad$ Smoking index & 0.04 & 0.8468 & 1.00 & $1.00-1.00$ \\
Anteroseptal infarction & 0.25 & 0.6152 & 0.83 & $0.41-1.70$ \\
Ischemic time (h) & 0.87 & 0.3511 & 1.04 & $0.95-1.13$ \\
Peak creatine kinase (IU/L) & 0.05 & 0.8205 & 1.00 & $1.00-1.00$ \\
Malignant arrhythmia & 0.05 & 0.8293 & 1.10 & $0.48-2.48$ \\
Collateral grade $<2$ & 10.42 & 0.0012 & 1.73 & $1.23-2.41$ \\
Left main coronary artery disease & 8.78 & 0.0031 & 4.98 & $1.72-14.41$ \\
Multivessel disease & 7.25 & 0.0071 & 2.94 & $1.34-6.44$ \\
Forrester subset $>2$ on admission & 6.51 & 0.0107 & 2.64 & $1.25-5.58$ \\
Pseudonormal filling pattern & 19.59 & 0.0001 & 1.97 & $1.96-1.99$ \\
LVDd dilation & 15.69 & 0.0001 & 4.24 & $2.08-8.68$ \\
LVEF $\leq 40 \%$ & 7.45 & 0.0063 & 1.06 & $1.00-1.12$ \\
LVWMSI $\geq 1.5$ & 1.03 & 0.3114 & 1.46 & $0.71-2.96$ \\
In-hospital time (days) & 0.38 & 0.5380 & 1.01 & $0.98-1.04$ \\
\hline
\end{tabular}
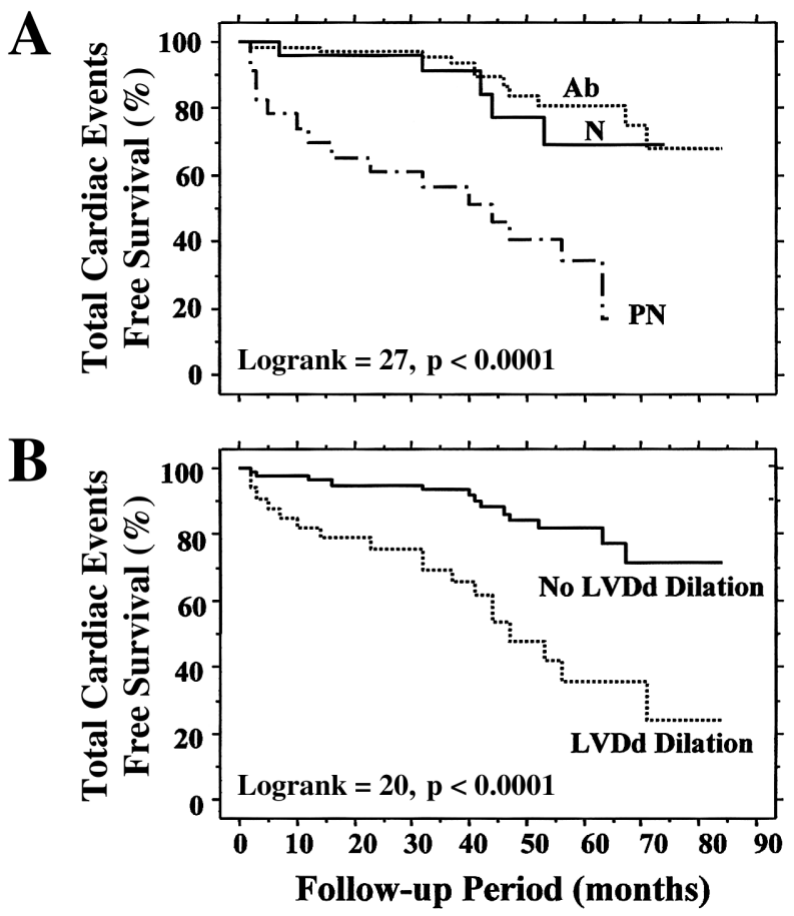

Fig 2. Kaplan-Meier survival curves drawn for total cardiac events in patients stratified by their transmitral flow pattern (A) and left ventricular end-diastolic diameter (B) on discharge after percutaneous coronary intervention. $\mathrm{N}$, normal transmitral flow pattern; $\mathrm{Ab}$, abnormal relaxation pattern; PN, pseudonormal transmitral flow pattern; LVDd, left ventricular end-diastolic diameter.

disease (exponential of coefficient: 13.8, chi-square: 9.4, $\mathrm{p}=0.05$ ) was the most powerful predictor of revascularization after PCI.

Total Cardiac Events Patients with PN and LV dilation had a significantly higher incidence of cardiac events. The other univariate significant predictors of cardiac event-free survival were hyperlipidemia, collateral grade $<2$, left main coronary artery disease, multivessel disease, Forrester subset class $>2$ on admission, PN, LV dilation, and decreased
LVEF $(\leq 40 \%)$ based on echocardiography at discharge (Table 5). Multivariate logical regression analysis also disclosed PN (chi-square: 6.7, $\mathrm{p}<0.01$ ) and LV dilation (chi-square: $9.4, \mathrm{p}<0.01$ ) at discharge as independent predictors of total cardiac events.

Total cardiac event-free survival curves revealed a significantly worse prognosis in patients with $\mathrm{PN}$ and LV dilation at discharge than in those with the $\mathrm{N}$ or $\mathrm{Ab}$ relaxation pattern (Fig 2A) and no LV dilation (Fig 2B).

\section{Discussion}

The present study has demonstrated, for the first time, the long-term prognostic value of echocardiography in patients with good coronary reflow (TIMI flow grade 3 ) after PCI for an initial AMI. The PN transmitral flow pattern and LV dilation at discharge could predict the occurrence of $\mathrm{CHF}$ and total cardiac events, but the other clinical, angiographic, or echocardiographic parameters could not.

Pathophysiology and Clinical Background of Patients With Angiographically Successful Reflow After PCI

The achievement of TIMI 3 flow in the infarct-related coronary artery is the primary goal of reperfusion therapy in patients with AMI, but patency of the vessel does not always mean myocardial perfusion in the related territory, as shown by studies using myocardial contrast echocardiography, positron emission tomography, ${ }^{13}$ radionuclide imaging, ${ }^{14}$ or intravascular ultrasound 15 In other words, angiographically successful reflow does not necessarily indicate adequate myocardial perfusion, because the ischemic episode can damage the coronary microvasculature and the flow to the infarcted myocardium may be reduced or absent (low-flow or no-reflow phenomenon) ${ }^{16}$ The no-reflow phenomenon is associated with extensive myocardial necrosis and microcirculatory damage!4-16

In this study, we showed that the combination of the PN transmitral flow pattern and LV dilation at discharge was associated with a higher incidence of cardiac events, even in patients in whom TIMI 3 flow in the infarct-related artery had been achieved after PCI. Therefore, echocardiography at discharge improves the identification of those 
patients who will have benefit from pharmacological adjunctive treatment to attenuate microvascular dysfunction and augment myocardial blood flow in the reperfused myocardium $!^{6-18}$

\section{Predictors of Long-Term Clinical Outcome in Patients With Angiographically Successful Reflow After PCI}

During the long-term follow-up period of this study no cardiac deaths occurred and the cumulative rates of $\mathrm{CHF}$ and nonfatal total cardiac events were $9.7 \%$ and $27 \%$, respectively. In patients with angiographically successful reflow after PCI for an initial AMI our univariate analysis revealed that hyperlipidemia, collateral grade $<2$, left main coronary artery disease, multivessel disease, Forrester subset class $>2$ on admission, PN transmitral flow pattern, LV dilation, decreased LVEF $(\leq 40 \%)$, and increased LVWMSI $(\geq 1.5)$ at discharge were the risk factors of remote CHF and/or nonfatal total cardiac events.

Early reperfusion of the infarct-related artery results in greater myocardial salvage and better LV function; ${ }^{19-21}$ however, it can be accompanied by reperfusion injury?22,23 When that occurs, the global LV systolic function does not improve immediately after reperfusion, instead it is deferred for a few days ${ }^{24}$ or some months, 25,26 a condition that is known as stunned myocardium ${ }^{27}$ The delayed improvement depends on several factors, such as the duration of ischemia before reperfusion, the degree of perfusion by means of collateral vessels, the severity of residual coronary stenosis after PCI, and the extent of the ischemic region? 24,28 In this setting, LVEF and LVWMSI, which are strong predictors of an adverse outcome, cannot predict the outcome because of the stunned myocardium and/or the compensatory hyperkinesia of the undamaged myocardium. In the present study, the echocardiographic LVEF and LVWMSI showed a strong prognostic significance in the univariate analysis, but it was lost in the multivariate logical regression analysis, and instead LVDd (dilated) and impaired LV diastolic function $(\mathrm{PN})$ at discharge were recognized as the most powerful predictors of a subsequent event. These results are consistent with previous observations ${ }^{29-31}$ and therefore, the importance of LV dilation and LV diastolic dysfunction in predicting long-term cardiac event-free survival should be recognized, irrespective of acute therapy and angiographically successful reflow after PCI.

\section{Relation Between LV Dilation, LV Diastolic Function and $\mathrm{CHF}$}

Progressive LV dilation after AMI, an important feature of $\mathrm{LV}$ remodeling, is strongly associated with adverse cardiovascular events and plays a particularly important role in the development of $\mathrm{CHF}^{32-34}$

Various factors have been considered influential in the development of LV remodeling, including infarct size, the perfusion status of the infarct-related artery $3^{33}$ the presence of asynergy ${ }^{35}$ and increased wall stress 32 During the longterm follow-up period of the present study, patients with LV diastolic dysfunction (PN transmitral flow pattern) and LV dilation developed CHF more often than those with $\mathrm{N}$ or Ab relaxation pattern without $\mathrm{LV}$ dilation. These observations suggest a link between $\mathrm{CHF}$ and LV diastolic dysfunction and/or LV dilation.

\section{Predictors of Revascularization After PCI}

In this study, echocardiographic variables were not selected as the predictors of revascularization after PCI. Other investigators have shown that chest pain and exercise stress testing following PCI are poor indicators of revascularization?6,37 Zellweger et al prospectively followed 356 patients who underwent coronary stenting and routine single-photon emission computed tomography (SPECT) imaging, and concluded that the extent and severity of ischemia as determined by SPECT was the best predictors of revascularization; ${ }^{38}$ however, cost limits the clinical application of SPECT. Ito et al used intracoronary myocardial contrast echocardiography to simultaneously assess regional wall motion and myocardial perfusion in patients with AMI, and showed that the contrast defect in the risk area immediately after PCI was a predictor of poor functional recovery5 Therefore, when intravenous myocardial contrast echocardiography develops further in the future, it may become a valuable modality for predicting revascularization as well as poor functional recovery after PCI.

\section{Study Limitations}

(1) This was not a randomized study, but comprised consecutive patients enrolled in a long-term echocardiographic and clinical evaluation program.

(2) All of the cardiac event-free survivors continued as outpatients for at least 3 years after the onset of AMI. Thus, we obtained most of the data by reviewing hospital charts and by direct interview with the patients, which ensured the accuracy of the data and reduced any minimal bias produced by interhospital discrepancy.

(3) The relatively small study population and the different frequencies of hyperlipidemia, left main coronary artery disease, and multivessel disease between the 2 groups may limit the statistical power for detecting predictors of longterm survival or revascularization after AMI.

(4) We could not successfully analyze the effects of the drugs that patients had received before the onset of AMI.

(5) In cases of right ventricular infarction, transmitral flow may become weaker for predicting remote clinical outcome because of the reduced preload, although we did use the echocardiographic data obtained within 1 week of discharge after PCI when the patients were stable and the loading condition was controlled well with medication.

\section{Conclusion}

Poor LV diastolic function and LV dilation at discharge may be predictors of cardiac events in the long-term in patients with angiographically successful reflow after PCI for an initial AMI.

\section{References}

1. Serruys PWJC, de Feyter P, MacayaC, Kokott N, Puel J, Vrolix M, et al. Fluvastatin for the prevention of cardiac events following successful first percutaneous coronary intervention. JAMA 2002; 287: $3215-3222$.

2. Okuda J, Kimura K, Kosuge M, Endo T, Sugano T, Nakatogawa T, et al. Significance of thrombolysis in myocardial infarction (TIMI) grade 2 flow early after thrombolysis followed by Immediate percutaneous coronary intervention in patients with acute myocardial infarction. Circ J 2003; 67: 238-242.

3. Grines CL, Browne KF, Marco J, Rothbaum D, Stone GW, O'Keefe $\mathrm{J}$, et al. A comparison of immediate angioplasty with thrombolytic therapy for acute myocardial infarction. N Engl J Med 1993; 328: $673-679$.

4. Morishima I, Sone T, Mokuno S, Taga S, Shimauchi A, Oki Y, et al. Clinical significance of no-reflow phenomenon observed on angiography after successful treatment of acute myocardial infarction with 
percutaneous transluminal coronary angioplasty. Am Heart $J$ 1995; 130: $239-243$.

5. Ito H, Tomooka T, Sakai N, Yu H, Higashino Y, Fujii K, et al. Lack of myocardial perfusion immediately after successful thrombolysis: A predictor of poor recovery of left ventricular function in anterior myocardial infarction. Circulation 1992; 85: 1699-1705.

6. Morishima I, Sone T, Okumura K, Tsuboi H, Kondo J, Mukawa H, et al. Angiographic no-reflow phenomenon as a predictor of adverse long-term outcome in patients with percutaneous transluminal coronary angioplasty for first acute myocardial infarction. $J$ Am Coll Cardiol 2000; 36: 1202-1209.

7. Xie GY, Berk MR, Smith MD, Gurley JC, DeMaria AN. Prognostic value of Doppler transmitral flow patterns in patients with congestive heart failure. J Am Coll Cardiol 1994; 24: 132-139.

8. Moller JE, Sondergaard E, Poulsen SH, Egstrup K. Pseudo-normal and restrictive filling patterns predict left ventricular dilatation and cardiac death after first myocardial infarction: A serial color M-mode Doppler echocardiographic study. J Am Coll Cardiol 2000; 36: $1841-1846$

9. Liu J, Tanaka N, Murata K, Ueda K, Wada Y, Oyama R, et al. Prognostic value of pseudo-normal and restrictive filling patterns on left ventricular remodeling and cardiac events after coronary artery bypass grafting. Am J Cardiol 2003; 91: 550-554.

10. Special report. The thrombolysis in myocardial infarction (TIMI) trial. N Engl J Med 1985; 312: 932-936.

11. Rentrop KP, Thornton JC, Feit F, Van Buskirk M. Determinants and protective potential of coronary collateral as assessed by angioplasty model. Am J Cardiol 1988; 61: 677-684.

12. Shiller NB, Shah PM, Crawford M, DeMaria A, Devereux R, Feigenbaum H, et al. Recommendation for quantification of the left ventrical by two dimensional echocardiography: American Society of Echocardiography Committee on Standards Subcommittee. $J$ Am Soc Echocardiogr 1989; 2: 358-367.

13. Maes AF, Van de Werf F, Mesotten LV, Flamen PB, Kuzo RS, Nuyts $\mathrm{JL}$, et al. Early assessment of regional myocardial blood flow and metabolism in thrombolysis in myocardial infarction flow grade 3 reperfused myocardial infarction using carbon-11-acetate. J Am Coll Cardiol 2001; 37: 30-36.

14. Hamada S, Nakamura S, Sugiura T, Murakami T, Fujimoto T, Watanabe J, et al. Early detection of the no-reflow phenomenon in reperfused acute myocardial infarction using technetium-99m tetrofosmin imaging. Eur J Nucl Med 1999; 26: 208-214.

15. Watanabe T, Nanto S, Uematsu M, Ohara T, Morozumi T, Kotani J, et al. Prediction of no-reflow phenomenon after successful percutaneous coronary intervention in patients with acute myocardial infarction: Intravascular ultrasound findings. Circ J 2003; 67: 667-671.

16. Taniyama Y, Ito H, Iwakura K, Masuyama T, Hori M, Takiuchi S, et al. Beneficial effect of intracoronary verapamil on microvascular and myocardial salvage in patients with acute myocardial infarction. $J$ Am Coll Cardiol 1997; 30: 1193-1199.

17. Kawaguchi R, Hoshizaki H, Oshima S, Hirathuji T, Adachi H, Toyama T, et al. Effectiveness of thrombectomy before stent implantation in acute myocardial infarction. Circ J 2003; 67: 951-954.

18. Marzilli M, Orsini E, Marraccini P, Testa R. Beneficial effects of intracoronary adenosine as an adjunct to primary angioplasty in acute myocardial infarction. Circulation 2000; 101: 2154-2159.

19. Gruppo Italiano per lo Studio della Streptochinasi nell'Infarto Miocardico (GISSI). Effectiveness of intravenous thrombolytic treatment in acute myocardial infarction. Lancet 1986; 1: 397-402.

20. The GUSTO Investigators. An international randomized trial comparing four thrombolytic strategies for acute myocardial infarction. $N$ Engl J Med 1993; 329: 673-677.

21. ISIS-3 (Third International Study of Infarct Survival) Collaborative Group. ISIS-3: A randomized comparison of streptokinase versus tissue plasminogen activator versus anistreplase and of aspirin plus heparin versus aspirin alone among 41,299 cases of suspected acute myocardial infarction. Lancet 1992; 339: 753-758.

22. Bolli R. Mechanism of myocardial 'stunning'. Circulation 1990; 82: $723-738$.

23. Bolli R. Myocardial 'stunning' in man. Circulation 1992; 86: 16711691.

24. Bourdillon PD, Broderick TM, Williams ES, Davis C, Dillon JC, Armstrong WF, et al. Early recovery of regional left ventricular function after reperfusion in acute myocardial infarction assessed by serial two-dimensional echocardiography. Am J Cardiol 1989; 63: 641-646.

25. Schmidt WG, Sheehan FH, Essen R, Uebis R, Effert S. Evolution of left ventricular function after intracoronary thrombolysis for acute myocardial infarction. Am J Cardiol 1989; 63: 497-502.

26. Knudsen AS, Darwish AZ, Norgaard A, Gotzsche O, Thygesen K. Time course of myocardial viability after acute myocardial infarction: An echocardiographic study. Am Heart J 1998; 135: 51-57.

27. Braunwald E, Kloner RA. The stunned myocardium: Prolonged postischemic ventricular dysfunction. Circulation 1982; 66: 11461149.

28. Zaret BL, Wackers FJT, Terrin ML, Ross R, Weiss M, Slater J, et al. Assessment of global and regional left ventricular performance at rest and during exercise after thrombolytic therapy for acute myocardial infarction: Results of the thrombolysis in myocardial infarction (TIMI) II study. Am J Cardiol 1992; 69: 1-9.

29. Shihara M, Tsutsui H, Tsuchihashi M, Tada H, Kono S, Takeshita A. In-hospital and one-year outcomes for patients undergoing percutaneous coronary intervention for acute myocardial infarction. Am J Cardiol 2002; 90: 932-936.

30. Hannan EL, Racz MJ, Arani DT, Ryan TJ, Walford G, McCallister BD. Short- and long-term mortality for patients undergoing primary angioplasty for acute myocardial infarction. J Am Coll Cardiol 2000; 36: $1194-1201$

31. Waldecker B, Waas W, Haberbosch W, Voss R, Heizmann H, Tillmanns H. Long-term follow-up after direct percutaneous transluminal coronary angioplasty for acute myocardial infarction. $J \mathrm{Am}$ Coll Cardiol 1998; 32: 1320-1325.

32. Pfeffer MA, Braunwald E. Ventricular remodeling after myocardial infarction: Experimental observations and clinical implications. Circulation 1990; 81: 1161-1172.

33. Gaudron P, Eilles C, Kugler I, Ertl G. Progressive left ventricular dysfunction and remodeling after myocardial infarction: Potential mechanisms and early predictors. Circulation 1993; 87: 755-763.

34. St John Sutton M, Pfeffer MA, Moye L, Plappert T, Rouleau JL, Lamas $\mathrm{G}$, et al. Cardiovascular death and left ventricular remodeling two years after myocardial infarction: Baseline predictors and impact of long-term use of captopril: Information from the Survival and Ventricular Enlargement (SAVE) trial. Circulation 1997; 96: 32943299.

35. McKay RG, Pfeffer MA, Pasternak RC, Markis JE, Come PC, Nakao $\mathrm{S}$, et al. Left ventricular remodeling after myocardial infarction: A corollary to infarct expansion. Circulation 1986; 74: 693-702.

36. Hernández RA, Macaya $C$, Iñiguez A, Alfonso $F$, Goicolea J, Fernandez-Ortiz A, et al. Midterm outcome of patients with asymptomatic restenosis after coronary balloon angioplasty. J Am Coll Cardiol 1992; 19: 1402-1409.

37. Ruygrok PN, Webster MWI, de Valk V, van Es GA, Ormiston JA, Morel MA, et al. Clinical and angiographic factors associated with asymptomatic restenosis after percutaneous coronary intervention. Circulation 2001; 104: 2289-2294.

38. Zellweger MJ, Weinbacher M, Zutter AW, Jeger RV, Mueller-Brand J, Kaiser C, et al. Long-term outcome of patients with silent versus symptomatic ischemia six months after percutaneous coronary intervention and stenting. J Am Coll Cardiol 2003; 42: 33-40. 